\title{
Role of Serum Glypican-3 in the Diagnosis of Hepatocellular Carcinoma in the Upper Egypt
}

\author{
Ali Abdelrahman Ghweil ${ }^{1}$, Ashraf Khodeary², Mohammed Tag-Adeen ${ }^{3 *}$, Marwa El-Sayed ${ }^{4}$, \\ Khaled Shahat ${ }^{5}$, Ghada Abdelrazek ${ }^{6}$
}

\footnotetext{
${ }^{1}$ Department of Tropical Medicine and Gastroenterology, Faculty of Medicine, South Valley University, Qena, Egypt

${ }^{2}$ Department of Clinical Pathology, Faculty of Medicine, Sohag University, Sohag, Egypt

${ }^{3}$ Department of Internal Medicine, Faculty of Medicine, South Valley University, Qena, Egypt

${ }^{4}$ Department of Medical Microbiology and Immunology, Faculty of Medicine, South Valley University, Qena, Egypt

${ }^{5}$ Department of Internal Medicine, Faculty of Medicine, Al-Azhar University, Cairo, Egypt

${ }^{6}$ Department of Diagnostic Radiology, Faculty of Medicine, South Valley University, Qena, Egypt

Email: alimenal@yahoo.com, khodery11@gmail.com, tagmedicine@gmail.com,nooreleiman1@yahoo.com,

khaledshahat27@yahoo.com,drghadarad2016@yahoo.com, *tagmedicine@gmail.com
}

How to cite this paper: Ghweil, A.A., Khodeary, A., Tag-Adeen, M., El-Sayed, M., Shahat, K. and Abdelrazek, G. (2018) Role of Serum Glypican-3 in the Diagnosis of Hepatocellular Carcinoma in the Upper Egypt. Open Journal of Gastroenterology, 8, 415-423.

https://doi.org/10.4236/ojgas.2018.811043

Received: October 28, 2018

Accepted: November 26, 2018

Published: November 29, 2018

Copyright $\odot 2018$ by authors and Scientific Research Publishing Inc. This work is licensed under the Creative Commons Attribution International License (CC BY 4.0). http://creativecommons.org/licenses/by/4.0/

\section{Open Access}

\begin{abstract}
Background and Aim: Early diagnosis of hepatocellular carcinoma (HCC) is essential for achieving good prognosis. Glypican 3 (GPC3) has been reported to be raised in HCC in comparison with non-neoplastic lesions. This work aimed to study the role of GPC3 in the early diagnosis of HCC in post-chronic hepatitis $\mathrm{C}(\mathrm{CHC})$ cirrhotic patients. Patients and Methods: A comparative study included 60 patients, 40 patients with HCC (HCC group) and 20 patients of CHC without HCC (control group). Diagnosis of HCC was based on abdominal ultrasound and triphasic CT, while biopsy was performed in debating cases. Serum samples for measurement of GPC 3 and AFP levels were obtained from all participants. Results: The median levels of both AFP and GPC3 were significantly higher among HCC cases compared to controls. Analysis of the ROC curve showed that both AFP and GPC 3 could be used to differentiate HCC cases from controls. AUROCs of GPC3 and AFP were 0.928 and 0.727 respectively, and both were statistically significant with p-values $<0.0001$. The best cut-off value for GPC3 for HCC detection was $3.15 \mathrm{ng} / \mathrm{ml}$ with $82 \%$ sensitivity (95\%CI: $67-93)$ and $95 \%$ specificity (95\%CI: 75 - 99), and for AFP it was $257 \mathrm{ng} / \mathrm{ml}$ with $77 \%$ sensitivity (95\%CI: $61-89$ ) and $85 \%$ specificity (95\%CI: $62-97$ ). Conclusion: Serum GLP-3 is highly sensitive and specific for detecting HCC, more than AFP for the early detection of HCC, and the combination of both yielded improved sensitivity.
\end{abstract}

\section{Keywords}

Hepatocellular Carcinoma, Alpha Fetoprotein, Glypican-3 


\section{Introduction}

Globally, hepatocellular carcinoma (HCC) is one of the most common cancers and represents the third most common cause of death worldwide [1] [2] [3]. The most important causes of HCC are liver cirrhosis, chronic hepatitis $\mathrm{C}$ (CHC) and chronic hepatitis $\mathrm{B}(\mathrm{CHB})$ infections, as well as fungal carcinogens, such as aflatoxin B1 [4].

According to the World Health Organization (WHO), around 3\% of the world's population are infected with hepatitis C virus (HCV), with its highest prevalence in Egypt ranging from $10 \%-20 \%$ of population; therefore, liver cancer represents around $12 \%$ of gastro intestinal malignancies [5] [6].

The HCC prognosis depends on number and size of tumors [7], which in turn depends on the lag time between the onset of HCC and the time of its diagnosis. However, HCC is usually asymptomatic or incidentally discovered during routine abdominal ultrasound (US) examination of cirrhosis, and most of detected lesions are locally advanced with limited therapeutic options [8] [9] [10].

As early HCC detection plays a crucial role for its proper management, regular screening for high-risk patients, including serum tumor markers as $\alpha$-fetoprotein, and imaging modalities, such as US, computed tomography (CT) or magnetic resonance imaging (MRI), is highly advised [11].

Alpha fetoprotein (AFP) is the most widely used serum tumor marker for the recognition and monitoring of HCC. The American Association for the Study of Liver Diseases (AASLD) guidelines recommended the use of AFP level $\geq 200$ $\mathrm{ng} / \mathrm{ml}$ instead of fine-needle cytology for HCC diagnosis especially in cirrhosis [12] [13] [14] [15]. However, serum AFP is not always elevated in all HCC patients, especially in lesions smaller than $5 \mathrm{~cm}$ in diameter. Moreover, its level may be elevated in non-malignant chronic liver diseases, such as chronic hepatitis and cirrhosis, and in other types of cancers, such as germ cell, stomach, biliary tract and pancreatic tumors, or even normally during pregnancy [14].

The glypican-3 (GPC3) is one of the glypican families of glycosyl phosphatidyl inositol (GPI)-anchored heparan sulfate proteoglycans [16], which plays an important role in cellular growth, differentiation and migration [17]. Higher GPC3 levels at both the mRNA and protein have been reported in HCC compared to pre-neoplastic and non-neoplastic lesions. The mRNA level of GPC3 was found to be much more elevated than AFP. This advantage of GPC3 over AFP was specially detected in the diagnosis of small HCC tumors [18]. The aim of the work was to evaluate the role of GPC3 in the early diagnosis of HCC in CHC-related cirrhotic patients.

\section{Ethical Clearance}

The study protocol was approved by the ethical committee of Qena Faculty of Medicine, South Valley University. A written informed consent was obtained from each participant in the study. 


\section{Patients and Methods}

\subsection{Patients Selection}

A total of 40 post-CHC cirrhotics with HCC were included in HCC group and 20 post- $\mathrm{CHC}$ cirrhotics without HCC were included as a control group. All patients were consecutively selected during their routine follow up in HCV clinic, Gastroenterology Department, South Valley University Hospital, Qena, Egypt between January 2017 and January 2018. Serum samples were obtained from all patients for routine investigations and GPC3 and AFP measurements.

\subsection{HCC Diagnosis}

Abdominal ultrasonography using Philips, ClearVue-650 system (Philips Electronics, Eindhoven, Netherlands) and triphasic CT using GE Healthcare-Brivo system (GE Healthcare, Chicago, IL, USA) were performed for all patients in order to diagnose or exclude HCC. Abdominal MRI using GE Healthcare-Signa Open Speed (GE Healthcare, Chicago, IL, USA) and biopsy were requested in debating cases with atypical lesions.

\subsection{AFP Measurement}

Serum AFP level was assessed by Mini Vidas system (Biomirieux, France) which is a compact automated immunoassay system based on the Enzyme Linked Fluorescent Assay (ELFA) principles.

\subsection{GPC3 Measurement}

Serum GPC3 level was measured using a (Quantikine ELISA kit) which is a solid phase sandwich enzyme linked immunosorbent assay done according to the manufacture pamphlet.

\subsection{Statistical Analysis}

Continuous variables were presented as means and standard deviations (SD), and $t$ test was used for comparison between means. Non-parametric variables were expressed as medians and ranges, and Mann Whitney test was used for comparison in-between medians. The percentages of positive AFP and GPC3 subjects in each group was calculated and compared to each other using Chi square test. ROC curve analysis was done to estimate the most relevant cut off values for both AFP and GPC3 to differentiate HCC cases from controls. Finally, univariate binary logistic regression analysis was done to estimate the predictive value of AFP and GPC3 for the diagnosis of HCC. The data were analyzed using the IBM-SPSS software version 24 (IBM corporation, 2016, Chicago, USA).

\section{Results}

The HCC group has included 40 patients, 9 females (22.5\%), with mean age of $59 \pm 9$ years (range: 46 - 72 years) while the control group has included 20 patients, 7 females (35\%), with mean age of $61 \pm 7$ years (ranged: $49-70$ years). 
Stages of HCC according to BCLC staging were very early HCC in 8, early HCC in 21, intermediate stage in 7 and advanced HCC in 4 patients.

Our result showed statistically significant differences between the levels of GPC3 and AFP in the study groups. The median GPC3 and AFP were significantly higherin the HCC group than in the control group (4.6 ng/ml versus 1.9, $\mathrm{p}$-value $<0.001)$ and $(1406 \mathrm{ng} / \mathrm{ml}$ versus 90.5 , $\mathrm{p}$-value $<0.001)$ respectively, Table 1.

In ROC curve analysis, GPC3 was an excellent HCC predictor with AUROC of $0.928(\mathrm{p}<0.001)$, while AFP was an average predictor with AUROC of 0.727 ( $p<0.001$ ), Figure 1 and Table 2. Univariate regression analysis showed both markers were statistically significant HCC predictors with p-values $<0.001$ and odds ratios: 5.895 (95\% CI: 2.226 - 15.616) for GPC3 and 0.03 and 1.004 (95\% CI: 1.000 - 1.008) for AFP respectively, Table 3. The most relevant cut off value of GPC3 for HCC detection was $3.15 \mathrm{ng} / \mathrm{ml}$ with $82 \%$ sensitivity (95\%CI: 67 93) and 95\% specificity (95\%CI: 75 - 99), and for AFP it was $257 \mathrm{ng} / \mathrm{ml}$ with $77 \%$ sensitivity (95\%CI: $61-89)$ and 85\% specificity (95\%CI: 62 - 97), Table 4. Adding GPC3 to AFP has improved specificity of both markers to $100 \%$ as all non-HCC patients in the control group had GPC3 and AFP levels lower than the determined cut off values, while the sensitivity showed little decrease to $72 \%$ (95\%CI: 56 - 85) as 29/40 HCC patients had GPC3 and AFP levels higher than the determined cut off values.

\section{Discussions}

HCC has bad clinical outcome with high mortality and a 5-year survival rate of less than 10\% from the time of clinical diagnosis [19]. In Egypt, HCC represents a major health problem because of its rising incidence and late detection which contributes to limited therapeutic options and unfavorable prognosis in most of cases. Therefore, it is highly recommended to find a new marker for screening and early detection of HCC [20] [21].

AASLD has recommended the use of GPC3, heat shock protein-70 and glutamine synthetase, because the co-positivity of any two of these three markers confirms the diagnosis of HCC [22]. Also, the Clinical Practice Guidelines of the European Association for the Study of the Liver (EASL) recommend these three markers for confirming HCC diagnosis [23] [24].

The aim of this study was to estimate the value of GPC3 as a diagnostic tool for early detection of HCC with $85 \%$ sensitivity and $100 \%$ specificity. Our study revealed that GPC3 level was significantly higher among HCC patients compared to controls. Several studies have demonstrated the efficacy of GPC3 ASA diagnostic tool in HCC, with a sensitivity ranged between $47 \%-90 \%$ and a specificity between $40 \%-100 \%$ [25] [26] [27]. This wide range of difference among studies may be attributed to different patients' demographic data and the use of different cut-off values for GPC-3 [28].

In a previous study by Zakhary et al., 2012 [29], among Egyptian patients with HCC on top of CHC, the sensitivity and specificity of AFP for differentiating 
Table 1. Comparison between GPC3 and AFP levels in HCC group and controls.

\begin{tabular}{cccccc}
\hline \multicolumn{2}{c}{ Marker } & HCC Group & Control Group & $\begin{array}{c}\text { Mann } \\
\text { Whitney }\end{array}$ & p value \\
\hline $\begin{array}{c}\text { GPC3 } \\
(\mathrm{ng} / \mathrm{ml})\end{array}$ & $\begin{array}{c}\text { Mean } \pm \mathrm{SD} \\
\text { Median }\end{array}$ & $5.95 \pm 3.51$ & $1.95 \pm 0.60$ & & \\
& (range) & $4.6(1.2-14.3)$ & $1.9(0.9-3.1)$ & 58 & $<0.001$ \\
AFP $(\mathrm{ng} / \mathrm{ml})$ & $\begin{array}{c}\text { Mean } \pm \mathrm{SD} \\
\text { Median } \\
\text { (range) }\end{array}$ & $1307.1 \pm 1040.0$ & $117.55 \pm 74.67$ & & \\
& $1406(11-3581)$ & $90.5(30-235)$ & 170.5 & $<0.001$ \\
\hline
\end{tabular}

Table 2. Area under the ROC curve of GPC3 and AFP.

\begin{tabular}{cccccc}
\hline \multirow{2}{*}{$\begin{array}{c}\text { Test Result } \\
\text { Variable (s) }\end{array}$} & Area & Std. Error & P value & \multicolumn{2}{c}{ Asymptotic 95\% Confidence Interval } \\
\cline { 5 - 6 } & & & & Lower Bound & Upper Bound \\
\hline GPC3 & 0.928 & 0.035 & $<0.001$ & 0.859 & 0.996 \\
AFP & 0.787 & 0.063 & $<0.001$ & 0.664 & 0.910 \\
\hline
\end{tabular}

Table 3. Univariate regression analysis of GPC3 and AFP.

\begin{tabular}{cccc}
\hline & p value & Odd's ratio & CI of Odd's ratio \\
\hline AFP & $0.035(\mathrm{~S})$ & 1.004 & $1.000-1.008$ \\
GPC3 & $<0.001(\mathrm{HS})$ & 5.895 & $2.226-15.616$ \\
\hline
\end{tabular}

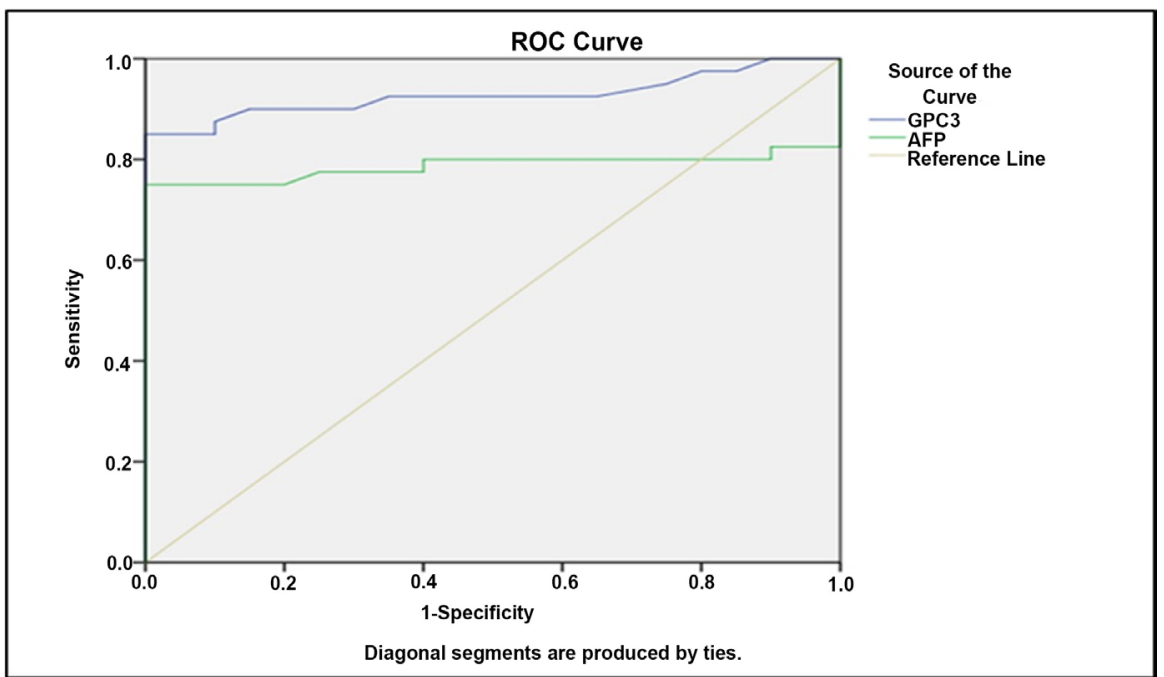

Figure 1. ROC curve analysis shows higher AUROC of GPC3 for prediction of HCC than that of AFP (0.92 vs 0.78$)$.

HCC from non-malignant liver disease at a cut-off level of $20 \mathrm{ng} / \mathrm{ml}$ were $90 \%$ and $34.0 \%$, respectively, and at a cut-off level of $100 \mathrm{ng} / \mathrm{ml}$ were $86.7 \%$ and $80 \%$, respectively.

Analysis of the ROC curve for both AFP and GPC3 in our study revealed that the most relevant cut-off value of GPC3 for HCC detection was $3.15 \mathrm{ng} / \mathrm{ml}$ and that of AFP was $257 \mathrm{ng} / \mathrm{ml}$, while in Zakhary et al., it was $3.8 \mathrm{ng} / \mathrm{ml}$ with $93.3 \%$ 
Table 4. Validity of GPC3 and AFP for HCC Diagnosis.

\begin{tabular}{|c|c|c|c|c|c|c|c|c|c|}
\hline \multirow[b]{2}{*}{ Markers } & \multicolumn{2}{|c|}{$\operatorname{HCC}(n=40)$} & \multicolumn{2}{|c|}{ Non-HCC $(n=20)$} & \multirow[b]{2}{*}{ Sensitivity } & \multirow[b]{2}{*}{ Specificity } & \multirow{2}{*}{$\begin{array}{c}\text { Positive } \\
\text { Predictive } \\
\text { Value }\end{array}$} & \multirow{2}{*}{$\begin{array}{c}\text { Negative } \\
\text { Predictive } \\
\text { Value }\end{array}$} & \multirow[b]{2}{*}{ Accuracy } \\
\hline & $\begin{array}{c}\text { True } \\
\text { Positive }\end{array}$ & $\begin{array}{c}\text { False } \\
\text { Negative }\end{array}$ & $\begin{array}{c}\text { True } \\
\text { Negative }\end{array}$ & $\begin{array}{c}\text { False } \\
\text { Positive }\end{array}$ & & & & & \\
\hline $\begin{array}{c}\text { GPC3 } \\
(\geq 3.15 \mathrm{ng} / \mathrm{ml})\end{array}$ & 33 & 7 & 19 & 1 & $\begin{array}{c}82 \% \\
(67-0.93)\end{array}$ & $\begin{array}{c}95 \% \\
(75-0.99)\end{array}$ & $\begin{array}{c}97 \% \\
(83-0.99)\end{array}$ & $\begin{array}{c}73 \% \\
(58-0.84)\end{array}$ & $\begin{array}{c}87 \% \\
(75-0.94)\end{array}$ \\
\hline $\operatorname{AFP}(\geq 257 \mathrm{ng} / \mathrm{ml})$ & 31 & 9 & 17 & 3 & $\begin{array}{c}77 \% \\
(61-0.89)\end{array}$ & $\begin{array}{c}85 \% \\
(62-0.97)\end{array}$ & $\begin{array}{c}91 \% \\
(78-0.97)\end{array}$ & $\begin{array}{c}65 \% \\
(51-0.77)\end{array}$ & $\begin{array}{c}80 \% \\
(68-0.89)\end{array}$ \\
\hline $\begin{array}{c}\text { Both GPC3 \& } \\
\text { AFP }\end{array}$ & 29 & 11 & 20 & 0 & $\begin{array}{c}72 \% \\
(56-0.85)\end{array}$ & $\begin{array}{c}100 \% \\
(83-0.100)\end{array}$ & $100 \%$ & $\begin{array}{c}64 \% \\
(52-.75)\end{array}$ & $\begin{array}{c}82 \% \\
(69-0.90)\end{array}$ \\
\hline
\end{tabular}

sensitivity and $100 \%$ specificity for GPC 3 and $151 \mathrm{ng} / \mathrm{ml}$ with $83.33 \%$ sensitivity and $100 \%$ specificity for AFP. The higher AFP cut-off in our result may be explained by inclusion of CHC patients as a control group in our study while normal subjects have been included in Zakhary et al.

However, other studies stated that GPC3 is not a useful diagnostic marker for HCC. This may be due to different measuring procedures used in these studies or different population characteristics [30].

Our study has many limitations including small sample size, single center study, lack correlation between GPC3 level and stage of HCC. Also, as CHC is the most common cause of liver cirrhosis and subsequent HCC in Egypt, our study was confined only to $\mathrm{CHC}$ patients without inclusion of patients with chronic hepatitis B or other liver pathogens. In conclusion, Serum GLP-3 is sensitive and specific for detecting HCC. Also, it is more sensitive than AFP for the early detection of HCC. Moreover, a combination of both markers yielded an improved benefit.

\section{Conflicts of Interest}

The authors declare no conflicts of interest regarding the publication of this paper.

\section{References}

[1] Llovet, J.M. (2006) Hepatocellular Carcinoma: Patients with Increasing Alpha-Fetoprotein but No Mass on Ultrasound. Clinical Gastroenterology and Hepatology : The Official Clinical Practice Journal of the American Gastroenterological Association, 4, 29-35.

[2] Yin, L., Cai, Z., Zhu, B. and Xu, C. (2018) Identification of Key Pathways and Genes in the Dynamic Progression of HCC Based on WGCNA. Genes, 9, No. 2. https://doi.org/10.3390/genes9020092

[3] Shibuya, K. and Yano, E. (2005) Regression Analysis of Trends in Mortality from Hepatocellular Carcinoma in Japan, 1972-2001. International Journal of Epidemiology, 34, 397-402. https://doi.org/10.1093/ije/dyh358

[4] Debruyne, E.N. and Delanghe, J.R. (2008) Diagnosing and Monitoring Hepatocellular Carcinoma with Alpha-Fetoprotein: New Aspects and Applications. International Journal of Clinical Chemistry, 395, 19-26.

[5] Morsi, M.I., Hussein, A.E., Mostafa, M., El-Abd, E. and El-Moneim, N.A. (2006) 
Evaluation of Tumour Necrosis Factor-Alpha, Soluble P-Selectin, Gamma-Glutamyl Transferase, Glutathione S-Transferase-PI and Alpha-Fetoprotein in Patients with Hepatocellular Carcinoma before and during Chemotherapy. British Journal of Biomedical SCIENCE, 63, 74-78. https://doi.org/10.1080/09674845.2006.11732724

[6] Habib, N.A., Mitry, R.R. and Sadri, R. (1998) p53 and Gene Therapy for Hepatocellular Carcinoma. Advances in Experimental Medicine and Biology, 451, 499-504. https://doi.org/10.1007/978-1-4615-5357-1_77

[7] Bruix, J. and Sherman, M. (2005) Management of Hepatocellular Carcinoma. Hepatology, 42, 1208-1236. https://doi.org/10.1002/hep.20933

[8] Wang, X.Q., Luk, J.M., Garcia-Barcelo, M., Miao, X., Leung, P.P., Ho, D.W., et al. (2006) Liver Intestine-Cadherin (CDH17) Haplotype Is Associated with Increased Risk of Hepatocellular Carcinoma. Clinical Cancer Research, 12, 5248-5252. https://doi.org/10.1158/1078-0432.CCR-06-0558

[9] Wang, X., Wei, Y., Yuan, S., Liu, G., Zhang, Y.L. and Wang, W. (2006) Potential Anticancer Activity of Litchi Fruit Pericarp Extract against Hepatocellular Carcinoma in Vitro and in Vivo. Cancer Letters, 239, 144-150. https://doi.org/10.1016/j.canlet.2005.08.011

[10] Stefaniuk, P., Cianciara, J. and Wiercinska-Drapalo, A. (2010) Present and Future Possibilities for Early Diagnosis of Hepatocellular Carcinoma. World Journal of Gastroenterology, 16, 418-424. https://doi.org/10.3748/wjg.v16.i4.418

[11] Lee, J.S., Heo, J., Libbrecht, L., Chu, I.S., Kaposi-Novak, P., Calvisi, D.F., et al. (2006) A Novel Prognostic Subtype of Human Hepatocellular Carcinoma Derived from Hepatic Progenitor Cells. Nature Medicine, 12, 410-416. https://doi.org/10.1038/nm1377

[12] Bruix, J. and Sherman, M. (2005) Diagnosis of Small HCC. Gastroenterology, 129, 1364. https://doi.org/10.1053/j.gastro.2005.08.046

[13] Phend, C. (2006) American Association for the Study of Liver Diseases (AASLD)-56th Annual Meeting. The Investigational Drugs Journal, 9, 96-100.

[14] Di Bisceglie, A.M. (2004) Screening for Hepatocellular Carcinoma: Being Old Is Not All Bad. The American Journal of Gastroenterology, 99, 1477-1478. https://doi.org/10.1111/j.1572-0241.2004.40195.x

[15] AFP Reviewers. (2017) Australian Family Physician, 46, 957-958.

[16] Capurro, M., Wanless, I.R., Sherman, M., Deboer, G., Shi, W., Miyoshi, E., et al. (2003) Glypican-3: A Novel Serum and Histochemical Marker for Hepatocellular Carcinoma. Gastroenterology, 125, 89-97. https://doi.org/10.1016/S0016-5085(03)00689-9

[17] Yamauchi, N., Watanabe, A., Hishinuma, M., Ohashi, K., Midorikawa, Y., Morishita, Y., et al. (2005) The Glypican 3 Oncofetal Protein Is a Promising Diagnostic Marker for Hepatocellular Carcinoma. Modern Pathology, 18, 1591-1598. https://doi.org/10.1038/modpathol.3800436

[18] Tangkijvanich, P., Chanmee, T., Komtong, S., Mahachai, V., Wisedopas, N., Pothacharoen, P., et al. (2010) Diagnostic Role of Serum Glypican-3 in Differentiating Hepatocellular Carcinoma from Non-Malignant Chronic Liver Disease and Other Liver Cancers. Journal of Gastroenterology and Hepatology, 25, 129-137. https://doi.org/10.1111/j.1440-1746.2009.05988.x

[19] Liu, A.M., Yao, T.J., Wang, W., Wong, K.F., Lee, N.P., Fan, S.T., et al. (2012) Circulating miR-15b and miR-130b in Serum as Potential Markers for Detecting Hepatocellular Carcinoma: A Retrospective Cohort Study. BMJ Open, 2, e000825. https://doi.org/10.1136/bmjopen-2012-000825 
[20] Ramadan, R.A., Madkour, M.A., El-Nagarr, M.M. and Abourawash, S.N. (2014) Serum Clusterin as a Marker for Diagnosing Hepatocellular Carcinoma. Alexandria Journal of Medicine, 50, 227-234. https://doi.org/10.1016/j.ajme.2014.05.004

[21] Debruyne, E.N., Vanderschaeghe, D., Van Vlierberghe, H., Vanhecke, A., Callewaert, N. and Delanghe, J.R. (2010) Diagnostic Value of the Hemopexin N-Glycan Profile in Hepatocellular Carcinoma Patients. Clinical Chemistry, 56, 823-831. https://doi.org/10.1373/clinchem.2009.139295

[22] Bruix, J., Sherman, M. and American Association for the Study of Liver D (2011) Management of Hepatocellular Carcinoma: An Update. Hepatology, 53, 1020-1022. https://doi.org/10.1002/hep.24199

[23] European Association for the Study of the Liver and European Association for the Study of the Liver (2012) EASL-EORTC Clinical Practice Guidelines: Management of Hepatocellular Carcinoma. Journal of Hepatology, 56, 908-943. https://doi.org/10.1016/j.jhep.2011.12.001

[24] European Association for the Study of the Liver and European Association for the Study of the Liver (2012) EASL-EORTC Clinical Practice Guidelines: Management of Hepatocellular Carcinoma. European Journal of Cancer, 48, 599-641. https://doi.org/10.1016/j.ejca.2011.12.021

[25] Qiao, S.S., Cui, Z.Q., Gong, L., Han, H., Chen, P.C., Guo, L.M., et al. (2011) Simultaneous Measurements of Serum AFP, GPC-3 and HCCR for Diagnosing Hepatocellular Carcinoma. Hepato-Gastroenterology, 58, 1718-1724. https://doi.org/10.5754/hge11124

[26] Liu, H., Li, P., Zhai, Y., Qu, C.F., Zhang, L.J., Tan, Y.F., et al. (2010) Diagnostic Value of Glypican-3 in Serum and Liver for Primary Hepatocellular Carcinoma. World Journal of Gastroenterology, 16, 4410-4415. https://doi.org/10.3748/wjg.v16.i35.4410

[27] Filmus, J. and Capurro, M. (2004) Glypican-3 and Alphafetoprotein as Diagnostic Tests for Hepatocellular Carcinoma. Molecular Diagnosis, 8, 207-212. https://doi.org/10.1007/BF03260065

[28] Badr, E.A.E., Korah, T.E., Ghani, A.A., El-Sayed, S. and Badr, S. (2014) Role of Serum Glypican-3 in the Diagnosis and Differentiation of Small Hepatocellular Carcinoma from Hepatitis-C Virus Cirrhosis. Alexandria Journal of Medicine, 50, 221-226. https://doi.org/10.1016/j.ajme.2014.01.002

[29] Zakhary, N.I., Mohamed, M.S., Khorshid, O., Azer, R.S. and Zayed, N. (2012) Role of Glypican-3 in the Early Diagnosis of Hepatocellular Carcinoma among Egyptian Patients. Journal of Genetic Engineering and Biotechnology, 10, 73-79. https://doi.org/10.1016/j.jgeb.2012.04.001

[30] Yasuda, E., Kumada, T., Toyoda, H., Kaneoka, Y., Maeda, A., Okuda, S., et al. (2010) Evaluation for Clinical Utility of GPC3, Measured by a Commercially Available ELISA Kit with Glypican-3 (GPC3) Antibody, as a Serological and Histological Marker for Hepatocellular Carcinoma. Hepatology Research, 40, 477-485. https://doi.org/10.1111/j.1872-034X.2010.00624.x 
List of Abbreviations in the Order of Appearance

\begin{tabular}{cccc}
\hline HCC & Hepatocellular Carcinoma & CHC & Chronic Hepatitis C \\
CHB & Chronic Hepatitis B & WHO & World Health Organization \\
HCV & Hepatitis C Virus & US & Abdominal Ultrasound \\
CT & Computed Tomography & MRI & Magnetic Resonance Imaging \\
AFP & Alpha Fetoprotein & GPC3 & Glypican-3 \\
AASLD & American Association for the Study of Liver Diseases
\end{tabular}

\section{Significance of the Study}

Hepatocellular carcinoma is the third most common cause of death worldwide and its earlier detection might help in a better prognosis. This study was conducted to study the role of a novel serum marker (Glypican 3) in the early detection of liver cancer. We concluded that glypican 3 is sensitive and specific for the early detection of liver cancer. 